Proceedings

\title{
Experimental Study on the Flow Boiling Heat Transfer Characteristics in a Mini-Channel with Offset Fins ${ }^{\dagger}$
}

\author{
Tao Wen ${ }^{1}$, Hongbo Zhan ${ }^{1}$, Yimo Luo ${ }^{2}$ and Dalin Zhang ${ }^{1, *}$ \\ 1 Department of Aircraft Environmental and Lift Supported Engineering, Nanjing University of Aeronautics \\ and Astronautics, Nanjing 210000, China; wentao@nuaa.edu.cn (T.W.); iseethink@126.com (H.Z.) \\ 2 Department of Construction Technology and Engineering, Technological and Higher Education Institute of \\ Hong Kong, Hong Kong 518000, China; luoyimo@gmail.com \\ * Correspondence: feitian010920215@163.com; Tel.: +86-0755-2698-4814 \\ † Presented at the Economy, Sustainable Development, and Energy International Conference (ESDEIC) 2018, \\ Edinburgh, UK, 25-27 June 2018.
}

Published: 28 October 2018

\begin{abstract}
The present study studied the flow boiling heat transfer performance of a mini channel with offset fins experimentally. The hydraulic diameter for it is $1.59 \mathrm{~mm}$ with 9 offset rectangular channels. The influences of saturation pressure, mass flux and heat flux on heat transfer coefficient were investigated. The experimental results reveal that when the vapor quality of refrigerant is less than 0.6, the mass flux has negligible influence on heat transfer coefficient. While it increases with both the saturation pressure and heat flux. Differently, in the high quality region, the heat transfer coefficient has an ascending trend with the increase of mass flux and is not affected by heat flux and saturation pressure.
\end{abstract}

Keywords: mini channel; offset fins; flow boiling heat transfer; refrigerant R134a

\section{Introduction}

The flowing boiling heat transfer in mini or micro channel has been considered as a promising solution for the high heat flux dissipation in a lot of areas, such as electronic devices cooling, micro reactor and micro heat exchanger [1]. Compared with the traditional channel, it has higher heat transfer efficiency, more compact structure. Due to its so many merits, it has drawn more and more attention in recent decades. However, few study on the mini channel with offset fins were carried out before.

Some researchers investigated the flow boiling heat transfer phenomenon in circle or rectangular mini channel [2,3]. As the channel with offset fins can disturb the boundary layer of flow and increase the turbulence, it has high heat transfer efficiency and has been widely used in the area of aviation for heat dissipation. Kim and Sohn [4] investigated the flow boiling heat transfer performance of R113 in a mini channel with offset fins with the equivalent diameter of $2.84 \mathrm{~mm}$. Pulvirenti et al. [5] studied the flow boiling heat transfer of HFE-7100 in a channel with offset strip fins with the equivalent diameter of $2.3 \mathrm{~mm}$. Their conclusion was that the channel with offset fins shown comparable heat transfer capacity with other kinds of channels under high heat flux. Recently, a $1.19 \mathrm{~mm}$ equivalent diameter channel with offset strip fins was adopted by Raju et al. [6] to study the flow boiling heat transfer of R134a. They employed the hot water channel to heat the refrigerant and only investigated the influence of mass flux on heat transfer characteristics. 
A rectangular mini channel with offset fins with the equivalent diameter of $1.59 \mathrm{~mm}$ was selected to its flowing boiling heat transfer characteristics. The effect of saturation pressure, mass flux and heat flux on heat transfer coefficient were experimentally investigated on a purpose-built test bench.

\section{Description of the Experimental System and Data Reduction}

\subsection{Experimental System}

The experimental system to study the flowing boiling heat transfer is shown in Figure 1. The operation processes during the experiments can be summarized as follows: before the experiment, the R134a refrigerant stored in the fin-tube condenser was cooled to the phase of subcooling. Then the valves in the refrigerant loop were opened expect those two connected with the test section. Driven by a gear pump, the R134a refrigerant could flow in the loop continuously. The two valves connected with the test section were opened after the pressure of refrigerant achieved to a steady state. A preheater which was heated by an electric heating film was used to regulate the inlet vapor quality of the test section. In order to evaporate the refrigerant in the mini channel, another electrical heating film made of Polyimide was employed. The heating film was connect with a DC power. By regulating the input current and voltage of it, the heating power could be easily acquired and controlled. Finally, the evaporated refrigerant flowed back to the receiver and condensed in the fintube condenser subsequently. A Coriolis mass flow meter with a measurement accuracy of $0.05 \%$ was used to measure the mass flow rate of refrigerant. The T-type thermocouple with an accuracy of 0.5 ${ }^{\circ} \mathrm{C}$ was adopted to acquire both the wall temperature of channel and the refrigerant temperatures. Two thermocouples were installed in the inlet and outlet seal head respectively to measure the inlet and outlet temperature of refrigerant. Two absolute pressure transducers with the accuracy of $0.02 \%$ were also installed before and after the tested channel to acquire the pressures.

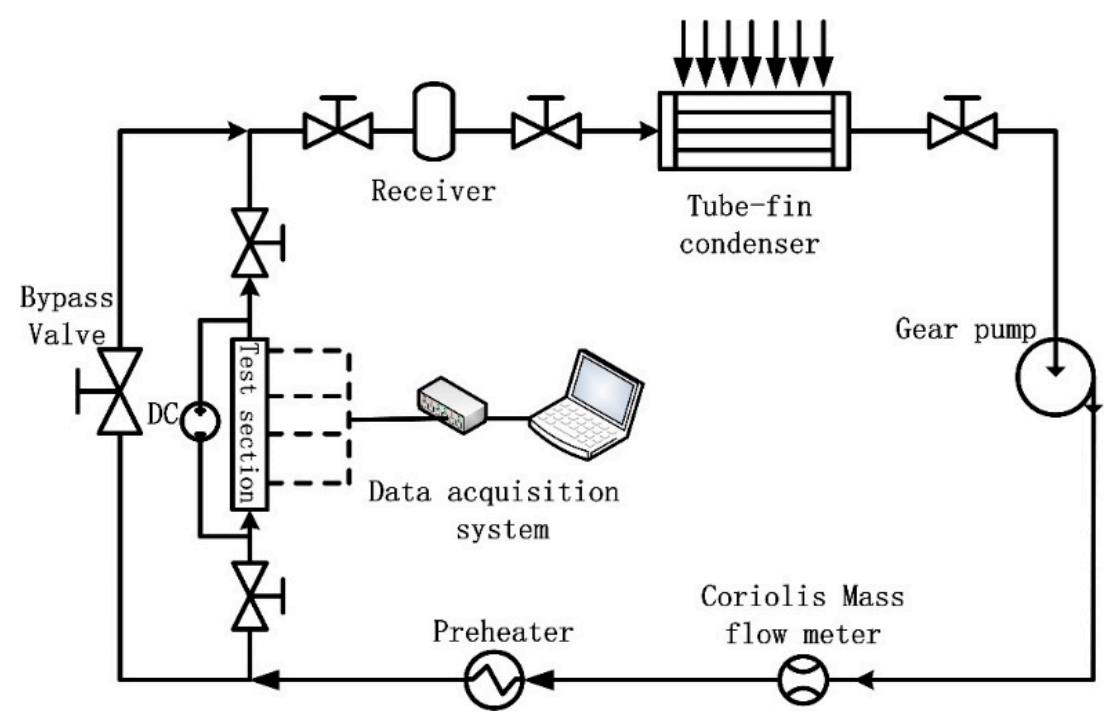

Figure 1. Schematic diagram of the experimental system.

\subsection{Experimental System}

Figure 2 illustrates the real picture of the tested mini channel and the assembly test section. For the mini channel with offset fins, it has 9 channels with the width and height of $1.50 \mathrm{~mm}$ and 1.70 $\mathrm{mm}$ respectively. The total length of the tested channel is $274 \mathrm{~mm}$. In order to uniformly distribute the refrigerant into the channel, two seal heads producing by 3D printing were adopted and installed before and after the test section. The tested channel was clipped between two polymethyl methacrylate plates by bolts. The electrical heating film was covered on the back surface of the tested channel. 10 thermocouples were adhered on the wall surface to get the local temperature. 

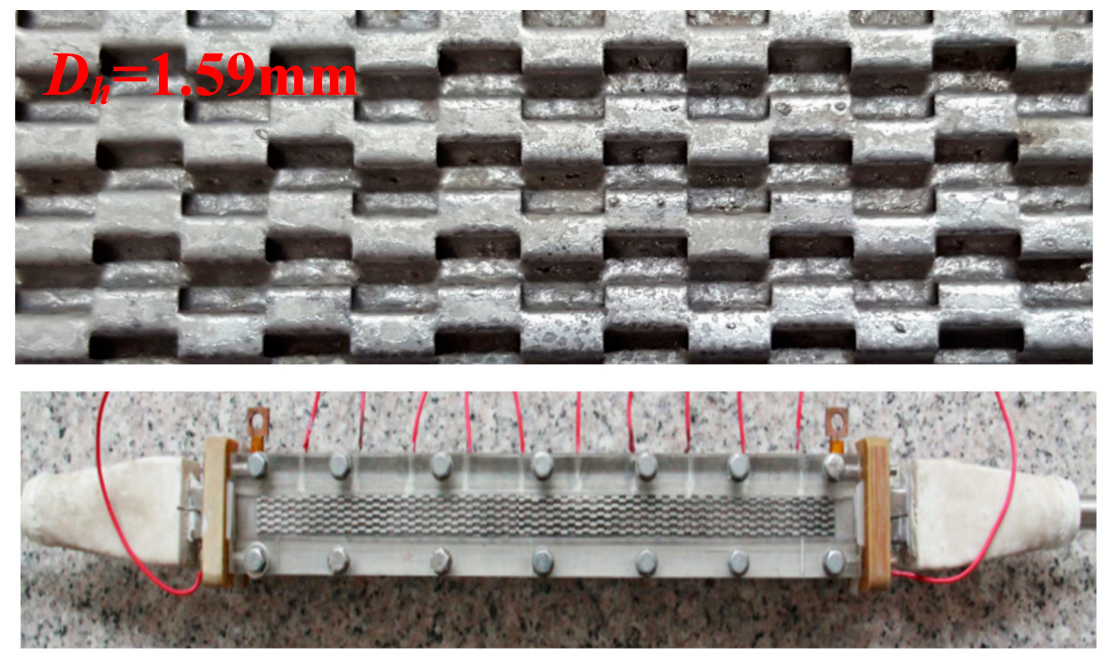

Figure 2. Real picture of the tested mini channel and test section.

\subsection{Experimental System}

The expression for the local flow boiling heat transfer coefficient is formulated in Equation (1) as follows:

$$
\alpha_{k}=\frac{q}{T_{w, k}-T_{s a t}}
$$

in which ${ }^{q}$ represents the heat flux. ${ }^{T_{w, k}}$ is the temperature of wall. $T_{\text {sat }}$ stands for the saturation temperature and is calculated by the saturation pressure $P_{\text {sat }}$. The definition for $P_{\text {sat }}$ is shown in Equation (2).

$$
P_{\text {sat }}=\frac{P_{i}+P_{o}}{2}
$$

where $P_{i}$ and $P_{o}$ denote the inlet and outlet pressure of refrigerant respectively.

The mass flux is formulated by the following equation:

$$
G=\frac{\dot{m}}{A_{c}}
$$

where $\dot{m}$ and $A_{c}$ are the mass flow rate and cross-sectional flow area correspondingly.

Equation (5) defines the the local vapor quality of refrigerant:

$$
x_{k}=\frac{h_{k}-h_{l, s a t}}{h_{g, s a t}-h_{l, s a t}}
$$

in which $h_{k}$ stands for the local enthalpy at the $k_{t h}$ measurement point. ${ }^{h_{g, s a t}}$ and $h_{l, s a t}$ are the saturation enthalpies of gas and liquid correspondingly.

\section{Experimental Results and Discussion}

\subsection{Effect of Saturation Pressure on the Heat Transfer}

Figure 3 presents the heat transfer coefficient of the tested mini channel with offset fins under different saturation pressure ranging from $0.28 \mathrm{MPa}$ to $0.42 \mathrm{MPa}$. It is obvious that when the vapor quality of refrigerant is less than 0.6 , the heat transfer coefficient increases with the increase of saturation pressure. However, beyond the vapor quality, the heat transfer coefficients tends to be the same under different saturation pressure. In another word, the influence of saturation pressure vanishes under high vapor quality region. 

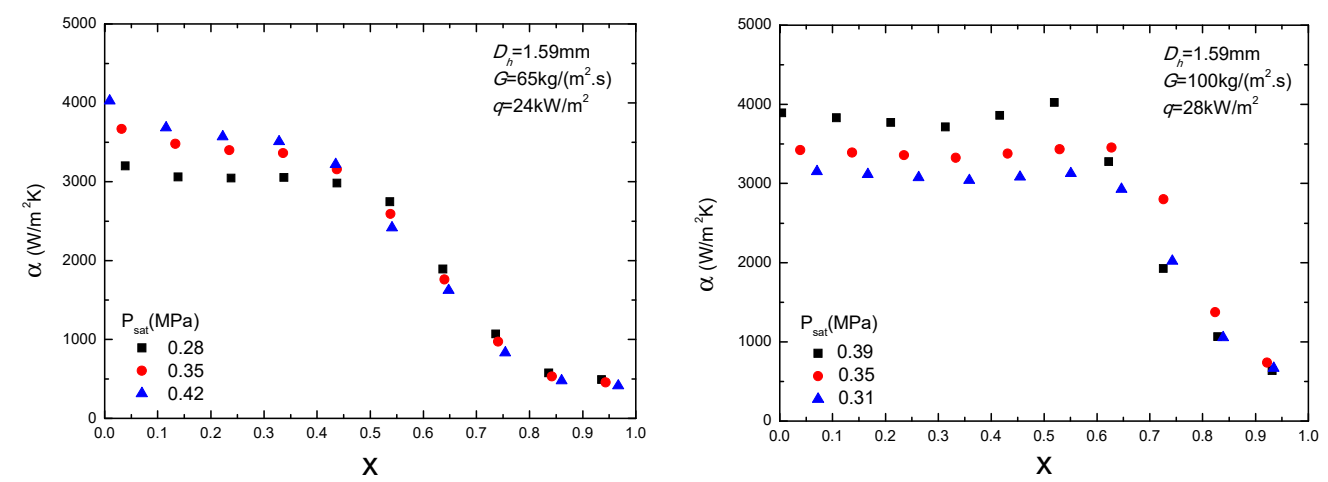

Figure 3. Effect of saturation pressure on heat transfer coefficient.

\subsection{Effect of Mass Flux on the Heat Transfer}

The heat transfer coefficients under different mass fluxes during flow boiling are illustrated in Figure 4. In the low and moderate vapor quality region, the heat transfer coefficient keeps constants and has little relationship with the mass flux. The interpretation is that nucleate boiling is dominant under the region and it is not influenced by the mass flux. However, under high vapor quality region, the convective boiling domains and greater mass flux corresponds to stronger convective boiling. As a result, the heat transfer coefficient increases with the mass flux in this region as shown in Figure 4.
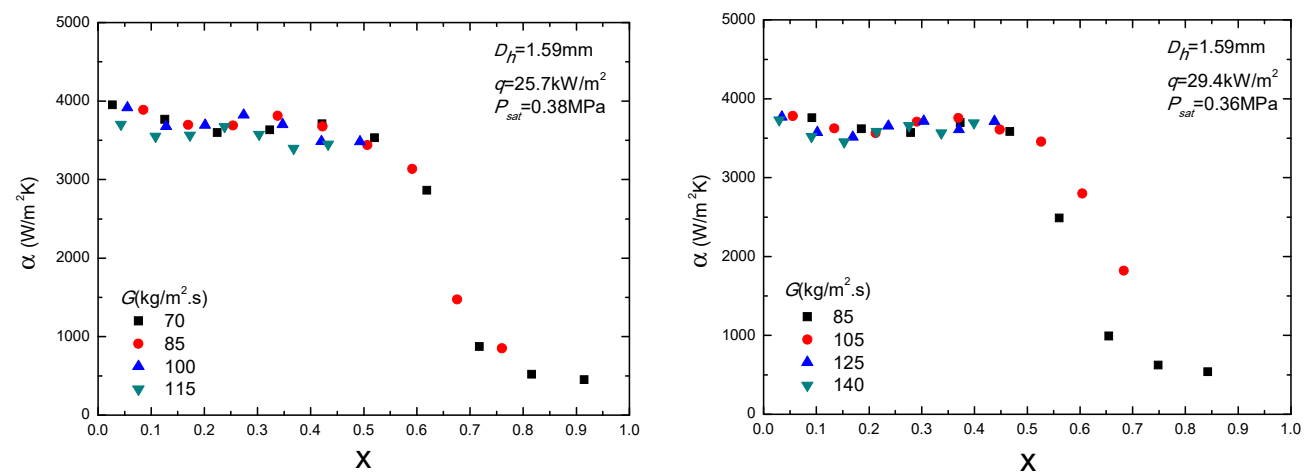

Figure 4. Effect of mass flux on the heat transfer coefficient.

\subsection{Effect of Heat Flux on the Heat Transfer}

Figure 5 presents the influence of heat flux on flow boiling heat transfer under different heat fluxes. It is clear that the heat transfer coefficient has an ascending trend with the increase of heat flux when the vapor quality is less than 0.6. For the mass flux of $70 \mathrm{~kg} /\left(\mathrm{m}^{2} \cdot \mathrm{s}\right)$ and saturation pressure of $0.3 \mathrm{MPa}$, the average heat transfer coefficient increases from $2847 \mathrm{~W} /\left(\mathrm{m}^{2} \cdot \mathrm{K}\right)$ to $3495 \mathrm{~W} /\left(\mathrm{m}^{2} \cdot \mathrm{K}\right)$ when the heat flux increases from $14 \mathrm{~kW} / \mathrm{m}^{2}$ to $25 \mathrm{~kW} / \mathrm{m}^{2}$. This can be contributed to the stronger nucleate boiling at higher heat flux. However, the influence of heat flux seems to vanish in high vapor quality region as demonstrated in Figure 5.
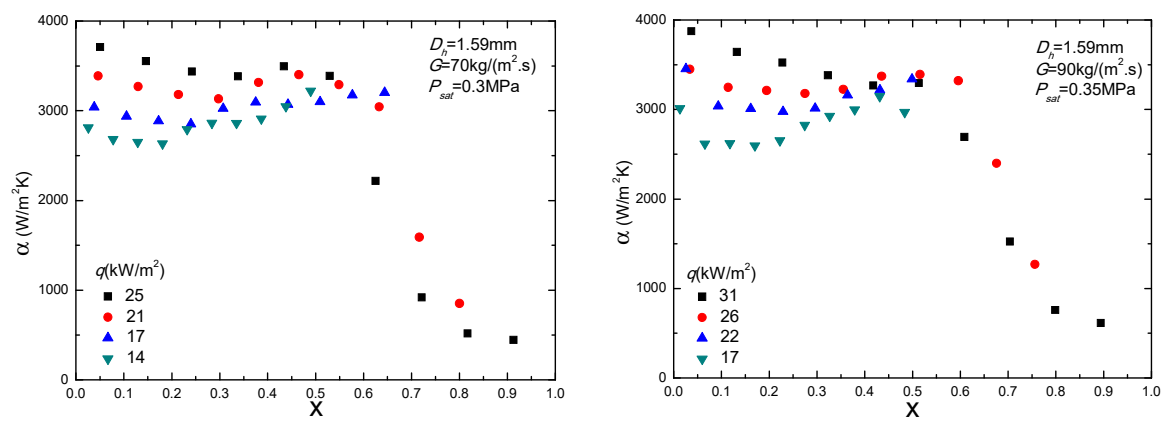

Figure 5. Effect of heat flux on the heat transfer coefficient. 


\section{Conclusions}

The flow boiling heat transfer characteristics in a mini channel with offset fins with the equivalent diameter of $1.59 \mathrm{~mm}$ were experimentally studied in present study. The results reveal that the heat transfer coefficient increases with the both saturation pressure and heat flux and shows little relationship with mas flux in low and moderate vapor quality region. However, in high vapor quality region, the influence of saturation pressure and heat flux seem to vanish and higher mass flux leads to greater heat transfer coefficient.

Author Contributions: T.W., H.Z. and D.Z. conceived and designed the experiments; T.W. and H.Z. analyzed the data; T.W. and Y.L. wrote the paper.

Acknowledgments: A Project Funded by the Priority Academic Program Development of Jiangsu Higher Education Institutions.

Conflicts of Interest: The authors declare no conflict of interest.

\section{References}

1. In, S.; Jeong, S. Flow boiling heat transfer characteristics of R123 and R134a in a micro-channel. Int. J. Multiph. Flow 2009, 35, 987-1000.

2. Saitoh, S.; Daiguji, H.; Hihara, E. Effect of tube diameter on boiling heat transfer of R-134a in horizontal small-diameter tubes. Int. J. Heat Mass Trans. 2005, 48, 4973-4984.

3. Wen, T.; Zhan, H.; Lu, L.; Zhang, D. Experimental investigation and development of new correlation for flow boiling heat transfer in mini-channel. Int. J. Therm. Sci. 2018, 129, $209-217$.

4. Kim, B.; Sohn, B. An experimental study of flow boiling in a rectangular channel with offset strip fins. Int. J. Heat Fluid Flow 2006, 27, 514-521.

5. Pulvirenti, B.; Matalone, A.; Barucca, U. Boiling heat transfer in narrow channels with offset strip fins: Application to electronic chipsets cooling. Appl. Therm. Eng. 2010, 30, 2138-2145.

6. Raju, M.A.; Babu, T.A.; Ranganayakulu, C. Flow boiling heat transfer and pressure drop analysis of R134a in a brazed heat exchanger with offset strip fins. Heat Mass Trans. 2017, 53, 3167-3180.

(C) 2018 by the authors. Licensee MDPI, Basel, Switzerland. This article is an open access article distributed under the terms and conditions of the Creative Commons Attribution (CC BY) license (http://creativecommons.org/licenses/by/4.0/). 